\begin{tabular}{|c|c|}
\hline & Asian Social Work Journal (ASWJ) \\
\hline $\begin{array}{c}\text { ASIAN SOCIAL WORK } \\
\text { JOURAL } \\
\text { (ASW) }\end{array}$ & Volume 4, Issue 1, February 2019 \\
& e-ISSN : 0128-1577 \\
& Journal home page: \\
& www.msocialwork.com \\
\hline
\end{tabular}

\title{
Cognitive Behaviour Therapy to Overcome Trauma of A Child Sexual Abuse Victim in Bandung-Indonesia
}

\author{
Ellya Susilowati ${ }^{1}, K$ risna Dewi ${ }^{1}$ \\ 1Bandung College of Social Welfare, Indonesia \\ Corrrespondence: Ellya Susilowati (ellyasusilowati1@gmail.com)
}

\begin{abstract}
Cognitive Behavior Therapy (CBT) is a micro social work intervention technique that can reduce trauma experience by victims of sexual violence, including children. The purpose of this study was to examine and analyze the application of CBT interventions in dealing with the trauma as experienced by a 10-year-old girl, a victim of sexual violence, who gets help from the Child Protection Agency (LPA) in Bandung. This study used experimental approach with Single Subject Design (SSD) with A-B measurement technique to show the impact of the interventions result. Trauma indications that are intervened with the CBT model are the fear of being alone, nightmare, and sadness when hearing the words related to rape or sexual violence. CBT interventions carried out in this study are performed by providing psychoeducation, relaxation, helping the victim to express feelings, teaching coping skills, and in vivo exposure. The results of CBT interventions indicated changes in the reduction in frequency of trauma indications in children who are victims of sexual violence. This proves that CBT interventions can be performed to reduce the trauma experienced by the 10-year-old victim of sexual violence. The recommendation that can be suggested based on the results of this study are; CBT should be carried out with a more complete session and give reinforcement to parents about mentoring traumatic child victims of sexual violence
\end{abstract}

Key words: cognitive behavior therapy, child sexual abuse victim, social work intervention

\section{Introduction}

Cases of sexual violence against children in Indonesia now is already alarming. News of the incidence of sexual violence that befell children are aired every day through printed and electronic media. Children who become the victims are at the ages of toddler to teenager. The data from the National Commission on Violence Against Women (Komnas Perempuan) showed an increase in the number of cases of sexual violence, that in 2014 the total of 3,860 cases of sexual violence were recorded and 6,499 cases of sexual violence including the ones against children were reported in 2015 . The incidents showed recorded in those period of two years showed an increase of 100 percent, as stated by the Indonesian Child Protection Commission. The data reinforced the results of the child abuse survey (2013) for both boys and girls, which stated that one of 12 boys experienced sexual violence and one of 16 girls experienced sexual assault (Puslitbang Kesos, 2013).

Sexual Violence is a criminal act related to sexuality that can be carried out against men or women (Susilawati, 2001:22). The causes that encourage predators to commit sexual violence against children according to Wickman \& West (2002) are categorized into two factors. First, Internal factors. The 
internal factors are already exist in individual, which include: a) Psychological factors, psychiatric conditions or abnormal self-condition of a person that can encourage the person to commit a crime. For example, abnormal sexual lust that causes perpetrators to commit sexual harassment to children as the victims by not being aware of the circumstances. The psychological (psychiatric) condition of someone who has been a victim of sexual violence in the past; b) Biological factor, including sexual needs. Sexual needs are just like other human basic needs that are needed to be fulfilled such as the need of eating; c). Moral factor, which is a factor to determine the incidence of crime. Sexual violence is might be caused by the very low moral level of perpetrators. Second, external factors. External factors are factors that influence from outside. The factors consist of: a) Socio-Cultural Factors, the increasing cases of immoral crime or sexual assault that are closely related to socio-cultural aspects. As a result of modernization, culture nowadays turns into more permissive and more free; b) Economic Factor, the difficulties in economic situation that make people to have low education level that significantly impact the good or bad of the deeds the people committed; c) Period Media Factor, the mass media as a means of information in sexual life. The news about sexual violence published in media that is often publicly reported and dramatized is generally described how satisfied the perpetrators after committing the wrong deed. This can give insight to readers and viewers of the news, especially those with evil mentality tendency, to get the idea of committing sexual assault to get the same satisfaction.

Howe (2005: 199) categorizes sexual activity contact into sexual contact and non-contact. Sexual contact contacts include penetrating actions (such as penile penetration or objects from the vagina, mouth, or anus) and non-penetrating actions (for instance, touching or sexually kissing a the sexual victim's body). Non-contact sexual activities including exhibitionism, involving children in making or consuming pornographic material, or encouraging two children to have sex together (Jones 2002: 1825 in Howe). Sexual contacts can be anything from touching the breast or genitals to oral, anal, or vaginal. The harassment may involve an adult who touches the child or a child who is forced to touch an adult. In some cases, sexual abuse involves some direct physical contact, for example, sexuality touching and/or kissing; teasing, rubbing and/or penetrating vagina or anus with fingers; oral sex; doing simulation of intimate relationship activities or penetration of the penis to vagina or anus. Sometimes, sex offenders may expose themselves (showing genitals or breasts) to children; also, children watch pornographic or sexual films; or maybe they film children while they are taking off their clothes with sexual purposes.

Children are often lured into those abusive sexual activities by being persuaded slowly or bribed by offering money, candy, and offered an assistance. Sometimes, they are intimidated or threatened. Adults may use the authority they have as "adults." And, often, they used their physical strength or violence to support their action. Whether the children are actually "injured" or not, whether they mind it or not, whether they like it or not, such sexual stimulation done by an adult or child who is coercive or older is considered as child sexual abuse and are potentially to give psychological danger for children.

The impact of sexual violence on children is cannot be neglected, not only causing physical damage but also causing psychological and social damages. Kendler et. al. (2000) explains the physical damage that is experienced by children depends on the ages, sizes and level of strength used by the perpetrators to commit the violence, the damage experienced by children can be in the form of internal injuries and bleeding. In severe cases, it can cause damage to internal organs and can even cause death. Some children might have an infection because their sexual organs are still immature causing further injury to the onset of infection. The terrible thing is the damage of the victims', the children's, future because of the psychological and social impacts they will get. Psychologically, children will experience trauma so that they lost their trust in adults and would experience sexual disorders when they grow up. Socially, they also would get stigma that can eliminate the sexual violence victims' chance to live a normal life.

Trauma in children who are victims of sexual violence will be a prolonged, long-lasting (Kendler at all, 2000; Zastrow, 2004; Howe, 2005; Lefkowiz, 2017) and even causes death (http://www.jurnalperempuan.org/ kekviolence-seksual-againstchild. html). Behavioral indications due to the trauma are shown by the fear the victims have, difficulty in sleeping, irritability, easily disturbed when hearing noise, difficulty in concentrating, and those kind of conditions that are likely to occur 
repeatedly. If those kind of signs are neglected, they will interfere the children's psychosocial development or children's mental health (Berliner \& Elliott, 2002; Briere \& Elliott, 2003; Chadwick Center, 2004).

The description of the trauma experienced by child victims of sexual violence is also seen in the case experienced by a child named APD, a 10-year-old girl who experienced sexual violence committed by her neighbor, a 73-year-old man. As a result of that terrifying experience, the child get emotional trauma as indicated by anxiety, introversion, withdrawal, sadness, often dreaming and showing delirious and fearful attitude that she often shows when she sees male adults. The trauma she get would long last for one year since the incident.

The trauma condition of child abuse need to immediately get serious treatment from various parties, especially from parents, families with the support of the community and the government. According to CASW (2005) services to children are provided through child service institutions, both organized by the government and the community whose tasks are to identify children who need protection and determine the best help and protection they can offer to child victims. The tasks of the child social service institution can be delegated to Social Workers who work at the institution. Social Workers can be involved in planning and offering various services for children and families, such as family support, institutional care, advocacy, adoption, foster family programs and child protection.

As a profession, in carrying out their duties to help children victims, Social Workers need to be based on the theories and the ability to apply social work intervention techniques as a process of giving assistance to the children who look for help to them, including victims of sexual violence. According to a research, Cognitive Behavior Therapy in particular Trauma Focus - Cognitive Behavior Therapy (TFCBT) gives positive results in helping to overcome the trauma of children who are victims of sexual violence. TF-CBT was originally used to help overcome feelings of fear, anxiety and depression in adults (Wolpe, 1969; Beck, 2011), but then this intervention model was used to help adults who were victims of rape who showed symptoms of PTSD (Foa et al, 1991) and also applied to children who have anxiety problems and excessive fear due to sexual violence they experienced (Beidel \& Turner, 1998).

CBT includes Cognitive Therapy and Behavioral Therapy. Cognitive Therapy is an attempt to change behavior by changing thoughts or perceptions that cause wrong or distorted views, while Behavioral Therapy is an attempt to change behavior that has become a habit of the same situation or stimulus. By performing CBT, it is expected that trauma experienced by APD can be reduced or healed, so that she can live a normal life again.

Based on the description that is afore mentioned, the researchers are interested in conducting research on the application of the CBT model in dealing with trauma experienced by APD who is a victim of sexual violence. The formulation of this research is: 'How is the application of the CBT model in dealing with trauma experienced by a child named APD, a victim of sexual violence?' In a more detail formulation of the problems: 1) How is the condition of APD who experienced trauma before the application of CBT?

\section{Research Methods}

This study used Single Subject Design (SSD), Belini and Akullian (2007) suggest that in the paradigm of behavior modification, SSD is the most prominent experimental approach and this design is most widely used in social work practices as an evaluation tool for interventions given by social workers to clients. This evaluation is done by looking at changes that occur in the same subject, by comparing conditions before and after receiving treatment (intervention). This research is an effort to measure the effect of intervention on a single subject. However, in this study, the measurement of the CBT model is to influence the trauma of children victims of sexual violence. The single subject here is a child named APD which is aged 10 years old. The measurement technique used was the A-B design to show the causal relationship between the dependent variable and the independent variable. A-B design research 
procedures done were: 1) Baseline Phase (A1), is the subject's initial condition before receiving treatment or intervention, so this condition is the basis for observation and assessment of the dependent variable. In this phase, the researchers measured the trauma of children who were victims of sexual violence, and the researchers obtained their basic data from the information conveyed by the parents of the children to the LPA about the condition of the child after experiencing sexual violence; 2) Intervention Phase (B) illustrated the subject's condition after getting interventions repeatedly in a sixday period. CBT interventions used to relieve subject trauma are: Sex abused education through pictures and films, Expressive therapy) Therapeutic games/activities, role plays, and take home exercises.

The research instruments used to measure trauma expressed by fearful behavior, nightmare and anger or shout. The researcher chose the frequency that is a calculation that shows how many times an event or behavior occurs within a certain time. The data collection techniques used in this research was done by recording the direct observation, that was done by recording the data of the dependent variable or target behavior when the behavior is happening. The Data Analysis Techniques used 'visual inspection analysis' where the analysis that was carried out through direct observation of the data that has been displayed in the graph and was analyzed by split method. In the first step, the data in each condition was divided into two parts. There were 6 data in phase A, so the two split lines are between the $3^{\text {rd }}$ and $4^{\text {th }}$ data. In Phase B, the data was divided into two parts, there were 6 data, the two lines are between the $3^{\text {rd }}$ and $4^{\text {th }}$ data. The next step was to determine the median. In both parts of the two split results in each phase ( $2 \mathrm{~b}$ ) so that there are 2 medians of 2 parts in one phase. The next step was to determine the estimated trend (trend line) by drawing a straight line that brought the two dividing lines $(2 \mathrm{~A})$ to the medium point (2B) at each phase.

\section{Results and Discussion}

The results of this study were analyzed through visual graphic presentation, namely data in condition A in the form of behavioral data before getting intervention and condition B in the form of behavioral data after getting intervention. The data analysis was carried out in accordance with the research method used, namely Single Subject Design (SSD) with A-B design (Engel \& Schut, 2014). The research subject was a 10 -year-old child as a victim of sexual violence who experienced trauma with traits of fearful behavior of going alone, experiencing nightmare and sadness when hearing the word related with rape. Variable $\mathrm{X}$ is an intervention in the form of CBT application while $\mathrm{Y}$ variable is the behavior of research subjects to be changed, namely the fear of being alone, nightmare and sadness when hearing the word related to sexual assault or sexual violence.

\section{Overview of institutions and research subjects}

Child Protection Agency (LPA) in West Java is an independent organization engaged in the social field of child protection with a vision to realize a life order that is able to prevent violations of children's rights and promote and protect children and their rights. The research subject was a girl with the initial named of APD, she was a client of the LPA. APD, a 10-year-old girl, is an elementary school child in grade 5 and lives in Ujung Berung District. APD is the first child of two siblings, his father and mother have been divorced since she was 5 years old, so APD often lives with his father at his grandfather's house. While her younger brother lives with his mother. APD's father works as a laborer, while her 41year-old mother works as a household assistant.

\section{Become a Victim of Sexual Violence}

APD is a victim of sexual violence (rape) of a 73-year-old neighbor. The terrifying incident was experienced by APD when she was 9 years old. At that time, she was in grade 3 of elementary school. APD lived with his father in his grandfather's house, and there was his grandfather's friend who often went to his grandfather's house. This grandfather often took care of APD, even gave her snacks so that one day the sexual violence happened. This incident was carried out more than once before finally the incident was reported to the police. The perpetrator is in a criminal law process in accordance with the 
Child Protection Act No. 35 of 2012. On the other hand, the child is handled by the Child Protection Agency (LPA) in Bandung, and get health and psychological services. After that incident, APD was taken care by her mother, she lives with her sister and grandfather from her mother. However, the child trauma cannot be disappeared, even her mother complained about the psychosocial condition of the child who become more silent and afraid to go alone, including when she is going to school. In fact, her mother who works as a domestic assistant has limited access to take care of her and send her to school every day. This trauma condition becomes prolonged and if it is not treated well, it might affect the psychosocial development of the child. The researchers, as social workers, try to deal with the child trauma by applying Cognitive Behavior Therapy (CBT).

\section{Initial conditions (base line)}

The results of the measurement of the initial conditions of the characteristics of APD behavior are as follows: 1) fear of being alone, this was stated at the time of the interview and the images made by the subject who stated that she was afraid of going alone, including when she should go to school. This condition causes the subject to be more silent at home; 2 ) often have nightmares, the subject explained that she often experiences nightmares; 3) feeling depressed when hearing the word related to rape or sexual violence. When she watches television, she often watch news about rape or sexual violence against children. She stated that "I feel sad when I hear the news". This is pictured by her silence, quite and moody. The following are measurements of the characteristics showed by APD : a) The Measurement of Fear of Being Alone. In the baseline phase, the fear of being alone seemed unstable, meaning that even though the research subjects always asked to be picked up while going home from school or studying the Quran, there were times when the subject dared to go home alone from the locations where she studies the Quran, which was relatively close to the house. This happened on the third and sixth days of observation. The fear of being alone experienced by the subject of the research is considered disturbing by her mother, because the mother of the research subject must work as a household assistant. The research subject should have dared to go alone to school or to the place of worship just like the children of her age.: b) Nightmare, indicated that the percentage of data stability is unstable. Even though the data is not stable but the variable level is close to zero (0) means that nightmare behavior rarely occured during the six (6) days observation period that it only occured twice (2). However, those nightmares are considered to interfere the research subject, although it rarely occured, because after she got nightmare, the research subject often cannot go back to sleep. As for the nightmares were in the form of frightening shadows that came approaching her; c) Feeling sad when hearing the word related to sexual violence. The measurement data shows that the frequency of the sadness feeling when hearing the word related to sexual violence is the same as the frequency of not feeling sad for six (6) days of observation. The sadness experienced by the subject of the study occurred when she heard the word related to sexual violence that she heard on TV. Then she also felt sad when her grandfather asked about the continuation of the service provided by the LPA on her by mentioning her as a victim of sexual violence.

Observation and measurement of the behavior during the six days observation showed that the subject was still experiencing prolonged trauma. This was in line with what stated by Kendler at all, 2000 and Lefkowiz, 2017. The protection service for the child to cope with her truma has not been done completely even her family still asks for the continuation of help from the accompanying institution. Her mother also felt confused to give help to the child, while she also experienced limitations. The research subject needs to get intervention because in everyday life she will often hear the words related to rape or sexual violence, that she hears on news in media and in everyday conversation.

\section{Intervention phase}

After being given an explanation of the purpose of the interventions to be given, the subject agreed and this was also supported by the subject's mother. CBT interventions that were given for six days are:

a. Psychoeducation for the child and parents. The researchers, as social workers, provided education about how to take self-care and avoid sexual violence, through the cartoon film "The Story of the Geni/Kisah si Geni" as an educational film produced by the Ministry of Women's Empowerment and 
Child Protection and UNICEF. This film is easily downloaded. This film provides education about: 1) to not accept gifts from strangers if there are no parents around, 2) To not participate in strangers' even though they are willing to give or buy something, 3) said "No", if there are people what to kiss you in a quite place, 4) said "No" if there is somebody who wants to hold your body, chest, abdomen and around the pants; 5) said "No" if somebody forces you, and must shout "No" and immediately "run" to a crowded place, and do not be afraid or ashamed to report that to parents, teachers or closed ones". The result of the observation showed that the subject of the study and her parents seemed listening to the film and grabbed the messages from the film.

b. Train relaxation. To reduce child trauma when remembering the traumatic events, children should be trained to do relaxation. The relaxation model provided is the 'Buble Blowee Magic' model which is done by: squeezing a ball (the ball can be made of paper) when remembering events that causes a child to be traumatized, so that the child diverts the emotion on a paper ball and can be relaxed.

c. Disclosure of feelings. Social workers facilitate the child to express her feeling by drawing various expressions of her condition/situation according to the situation she felt, for example sad, happy or just so-so.

d. Teach coping skills, by writing letters when facing unpleasant situations;

e. In vivo exposue, to familiarize the child to the situation of trauma, such as dealing with words related to rape or sexual violence

The researchers measured trauma behavior in the subject at the time of interventions, and compared the results of behavioral measurements before intervention. The following are graphs of the measurement results before and during the interventions.

\section{a) Measurement of Fear of Being Alone}

Based on Figure 1, it shows that in the baseline phase (A) the occurrence of the increase of fear of being alone is marked by a broken line (). In the intervention phase (B) it tends to decrease which means there is a decrease in fear behavior going alone. In the baseline phase (A) the range is 1.52 1.82 and in the intervention phase (B) the range is $0.225-0.375$ The range in the intervention phase (B) is lower than the baseline phase (A). The differences in those ranges prove that the condition of fear of being alone experienced by APD has decreased as a result of the intervention phase (B).

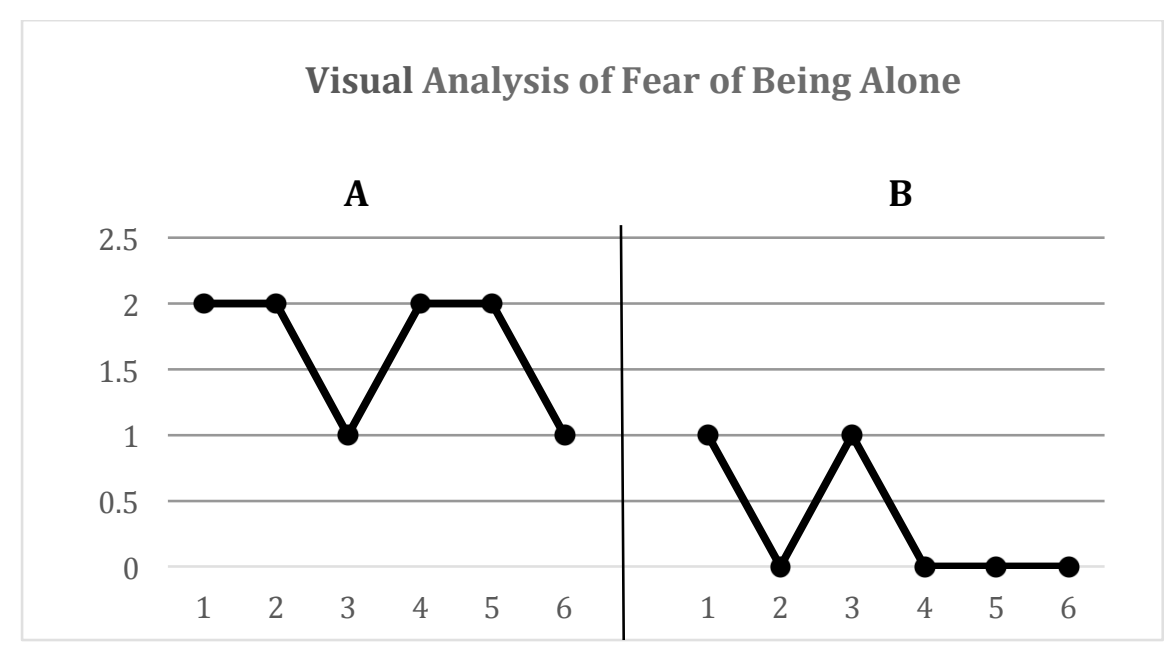

Figure 1 : Visual Analysis of Fear of Being Alone Experienced by APD 


\section{b) Visual analysis of nightmare experience}

The following is a graphic picture of nightmare expereinced by APD in phase A (before intervention) and measurement results in phase B (after being given CBT interventions based on behavioral observations):

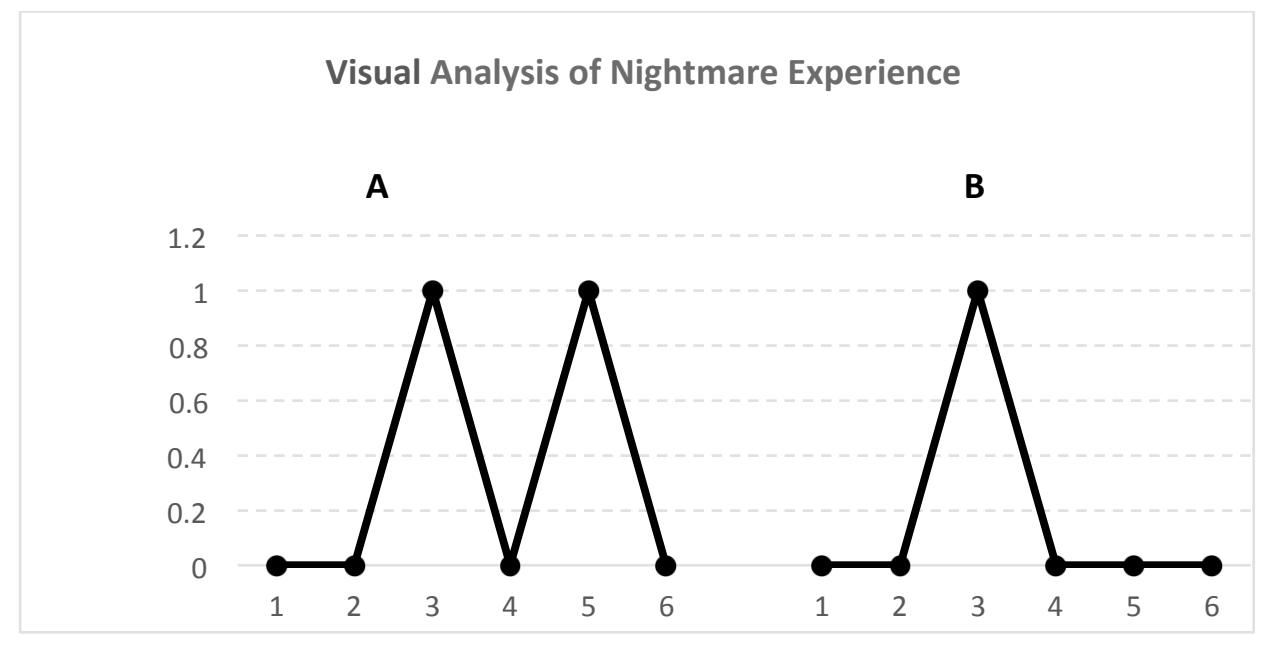

Figure 2: Visual analysis of nightmare Expereinced by APD

Figure 2 shows that in the baseline phase (A) the increases indicates an increase in nightmare behavior. In the intervention phase (B) it tends to decrease that means there is a decrease in fear of being alone. In the baseline phase (A) the range is $0.225-0.375$ and in the intervention phase (B) the range is 0.235 -0.085 the range in the intervention phase (B) is lower than the baseline phase (A). Those differences in the ranges prove that the nightmare expereince decreased as a result of the intervention phase/treatment of CBT in phase B are given.

\section{c) Visual Analysis of Feeling Sad When Hearing the Words Related to Rape of Sexual Violence}

The following is the graphic picture of Feeling Sad When Hearing the Words Related to Rape of Sexual Violence in phase A before intervention and measurement results got and in phase B at the time after being given CBT intervention based on the behavioral observations.

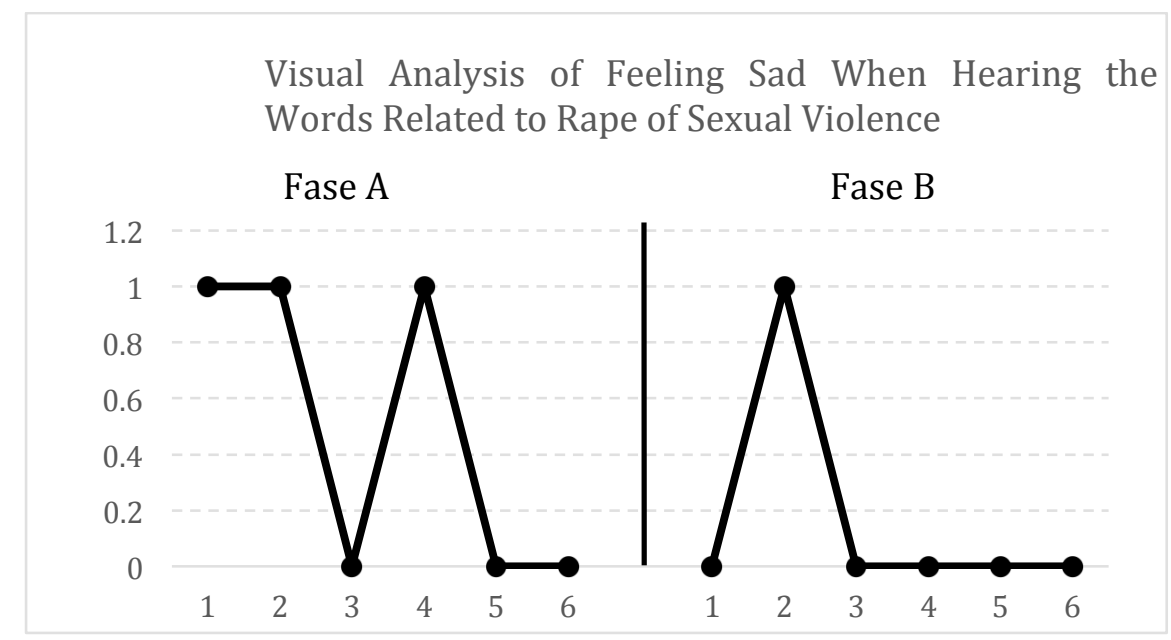

Figure 3. Visual Analysis Feeling Sad When Hearing the Words Related to Rape of Sexual Violence Experienced by APD 
Figure 3 shows that baseline phase (A) decreases and is marked $(+)$ which indicates a decrease in Feeling Sad When Hearing the Words Related to Rape of Sexual Violence. In the intervention phase (B) it tends to decrease and is marked $(+)$ meaning there is a decrease in Feeling Sad When Hearing the Words Related to Rape of Sexual Violence. In the baseline phase (A) the range is $0.425-0.575$ and in the intervention phase (B) the range is $0.235-0.085$ The range in the intervention phase (B) is lower than in the baseline phase (A). The differences in these ranges prove that the condition of Feeling Sad When Hearing the Words Related to Rape of Sexual Violence has decreased as a result of the phase of interventions of CBT (B). Figure 3 shows that the level of change in the baseline phase (A) experienced a change as much as 1 point and was positive, which means that a positive change was seen in the baseline phase (A). The level of change in the intervention phase (B) is 0 , which means that there is no significant change if the first and last score data are compared.

Of the three measurements showed that the traumatized child can bring up three types of behavior at once: Fear of Being Alone, Fear of Feeling Sad When Hearing the Words Related to Rape of Sexual Violence, and Nightmare Expereince. CBT interventions through psychoeducation stages in children and parents, practicing relaxation, expressing feelings, teaching coping skills, and In vivo exposue can affect children's cognitive and behavior so it can be used to reduce or overcome trauma in children. It explains that what was put forward by Foa et al, 1991 and Beidel \& Turner, 1998 that CBT can be applied to children who have anxiety problems and excessive fear due to sexual violence they experience.

\section{Conclusions and Recommendations}

The results of the study concluded that children who were victims of sexual violence who were accompanied by LPA were still experiencing prolonged trauma, which was marked by fear of being alone, nightmare and sadness feeling when they heard or saw something related to sexual violence in children. Cognitive Behavior Therapy (CBT) with stages of giving psychoeducation to children and parents, practicing relaxation, expressing feelings, teaching coping skills, and In vivo exposue proven to reduce trauma in children. However, in this study, the researchers had limited time so they only measured trauma behavior for as long as six days in the initial condition, and six days during the intervention took place with the Single Subject Design model of the A-B method. To improve the intervention or application of CBT on trauma to children, the recommendations are: 1) 1. LPA should refer to social workers to assist in reducing trauma experienced by children until the children can function socially; 2) Social Workers for Children intervene in CBT with more complete sessions and sufficient time; 3) Parents of child victims of sexual violence receive training on childcare that requires special protection; 4) If parents are unable to follow, and child trauma continues, the children can be rehabilitated socially into the Child Social Protection House (Rumah Perlindungan Sosial Anak or RPSA) in Bambu Apus. For further research, it is recommended: 1) the application of CBT should be done in full session; 2) gather family and community support to handle child abuse victims.

\section{References}

AB Rowan, DW Foy, N Rodriguez, S Ryan - Child Abuse \& Neglect, 1994 - Elsevier Beck, Aaron (2011). Cognitive Behaviour Therapy. Basic and Beyond. New York. The Guilford Press. Beidel, D.C. and Turner, S.M. (1998). Shy children, phobic adults: The nature and treatment of social phobia. Washington, DC: American Psychological Association

Belini and Akullian (2007). A meta-analysis of video modeling and video self-modeling interventions for children and adolescents with autism spectrum disorders. Exceptional Children, 73(3), 264287

Berliner, L. and Elliott, D.M. (2002). Sexual abuse of children. In J.E.B. Myers, L. Berliner, J. Briere, C.T. Hendrix, C., Jenny, and T.A Reid (Eds.), The APSAC handbook on child maltreatment (pp. 55-78). Thousand Oaks, CA, US: Sage Publications, Inc 
Briere, J., and Elliott, D.M. (2003). Prevalence and psychological sequelae of self-reported childhood physical and sexual abuse in a general population sample of men and women. Child Abuse \& Neglect, 27(10), 1205-1222

Chadwick Center (2004). Closing the quality chasm in child abuse treatment: Identifying and disseminating best practices. San Diego, CA: Author

CASW (2005). Code of Ethics and Guidelines for Ethical Practice.

Corby, Brian (2006). Child abuse . Open Univesrsity Press. New York.USA

Engel, Rafael J \& Schutt, Russel K (2014). Fundamentals of Social Work Research. Second Edition. Sage. Los Angeles

Foa et al (1991). EB Foa, BO Rothbaum, DS Riggs, TB Murdock Treatment of posttraumatic stress disorder in rape victims: a comparison between cognitive-behavioral procedures and counseling. Journal of Affective Disorders, 1(1984), pp. 269-277

Friedberg, Robert D, McClure.Jessica \& Garcia, Jolene Hillwig (2009). Cognitive Therapy Techniques for Children and Adolescent. The Guilford Press. New York- London

Howe, David (2005). Child Abuse and Neglect. Attachment, Development ant intervention. Palgrave Macmilan. NY

Juang Sunanto, Takeuchi Koji \& Hideo Nakata (2006). Penelitian dengan Subyek Tunggal. UPI Press Zastrow (2004) The Practice of Social Work. Brooks/Cole Publishing Company. New York.

KS Kendler, CM Bulik, J Silberg (2000) Childhood sexual abuse and adult psychiatric and substance use disorders in women: an epidemiological and cotwin control analysis Archives of general ..., 2000 - jamanetwork.com

Lorie Elizabeth Anderson, Elisabeth A. Weston, Howard J. Doueck and Denise J. Krause. The Child Centered Social Worker and the Sexually Abused Child: Pathway to Healing. Social Work Vol. 47(4), 368-378

Payne, Malcom (2014). Modern Social Work Theory. Palgrave, Macmillan

Puslitbang Kesos, 2013. Survei Kekerasan Terhadap Anak.

Ronen, Tammie, \& Freeman, Arthur (2007). Cognitive-Behavior Therapy in Clinical Social Work Practice.

Undang Undang No 35 tahun 2014 tentang perubahan atas UU NO 23 thun 2002 tentang Perlindungan Anak

Wickham, Randall Easton and West, Janet (2002), Therapeutic work with sexually abused children. London: Sage.Publication .Ltd.

Wolpe, Joseph (1969). Basic principles and practices of behavior therapy of neoroses.American Journal of Psychiatri, 125(9), 12-42-1247.

Zastrow (2004) The Practice of Social Work. Brooks/Cole Publishing Company. New York. 